Review

\title{
The Potential for Resident Lung Mesenchymal Stem Cells to Promote Functional Tissue Regeneration: Understanding Microenvironmental Cues
}

\section{Robert F. Foronjy ${ }^{1}$ and Susan M. Majka ${ }^{2, *}$}

1 Department of Medicine, St. Luke's Roosevelt Health Sciences Center, Antenucci Building, 432 West 58th Street, Room 311, New York, NY 10019, USA; E-Mail: rforonjy@chpnet.org; Tel.: +1-212-523-7265

2 Department of Medicine, Vanderbilt University, 1161 21st. Ave S, T1218 MCN, Nashville, TN 37232, USA

* Author to whom correspondence should be addressed; E-Mail: susan.m.majka@Vanderbilt.edu; Tel.: +1-303-883-8786.

Received: 28 August 2012; in revised form: 19 September 2012 / Accepted: 25 September 2012 / Published: 19 October 2012

\begin{abstract}
Tissue resident mesenchymal stem cells (MSCs) are important regulators of tissue repair or regeneration, fibrosis, inflammation, angiogenesis and tumor formation. Bone marrow derived mesenchymal stem cells (BM-MSCs) and endothelial progenitor cells (EPC) are currently being considered and tested in clinical trials as a potential therapy in patients with such inflammatory lung diseases including, but not limited to, chronic lung disease, pulmonary arterial hypertension (PAH), pulmonary fibrosis (PF), chronic obstructive pulmonary disease (COPD)/emphysema and asthma. However, our current understanding of tissue resident lung MSCs remains limited. This review addresses how environmental cues impact on the phenotype and function of this endogenous stem cell pool. In addition, it examines how these local factors influence the efficacy of cell-based treatments for lung diseases.
\end{abstract}

Keywords: mesenchymal stem cell; lung disease; hypertension; fibrosis; pulmonary regeneration; PDGF-BB; Wnt; sfrp 


\section{Introduction}

Many lung diseases are driven by the maladaptive proliferation of vascular and myofibroblast cells that results in dysfunctional lung remodeling. This cellular response occurs in a significantly altered pulmonary microenvironment that impedes the normal repair and regenerative capacity of tissue resident stem cells [1]. Current paradigms define the origin of these proliferative myofibroblasts as bone marrow, vascular and epithelial derived via transdifferentiation events. However, recent studies challenge this paradigm and indicate that lung MSCs are triggered by local factors to differentiate into myofibroblasts that contribute to disease progression (Figure 1). Therefore, understanding the molecular and cellular basis of endogenous lung mesenchymal stem cell (lung MSCs) participation in lung injury and repair is of critical importance. This review explores the role of the PDGF-BB and Wnt signaling pathways in the differentiation and proliferation of lung MSCSs in pulmonary diseases. Moreover, it explores the potential of manipulating these pathways to promote lung MSCs participation in functional tissue regeneration. Understanding these signaling responses may lead to new strategies that harness the reparative capacity of lung MSCs while preventing their participation in dysfunctional remodeling processes.

Figure 1. Schematic representation of the microenvironmental influences on resident lung mesenchymal stem cell function during tissue homeostasis and disease.

\section{$\underline{\text { Tissue Homeostasis }}$}

Idiopathic Pulmonary Fibrosis

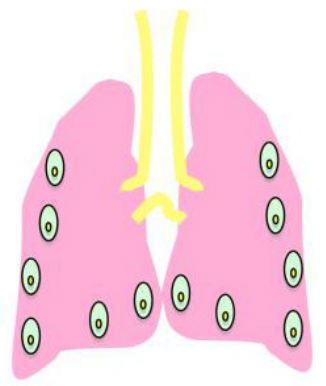

Release of local signaling factors

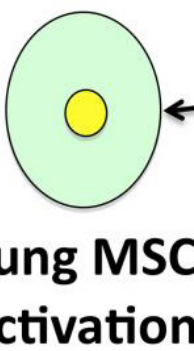

Myofibroblast

- Proliferative

- Synthetic (collagen, elastin)

- Inflammatory

-Contractile

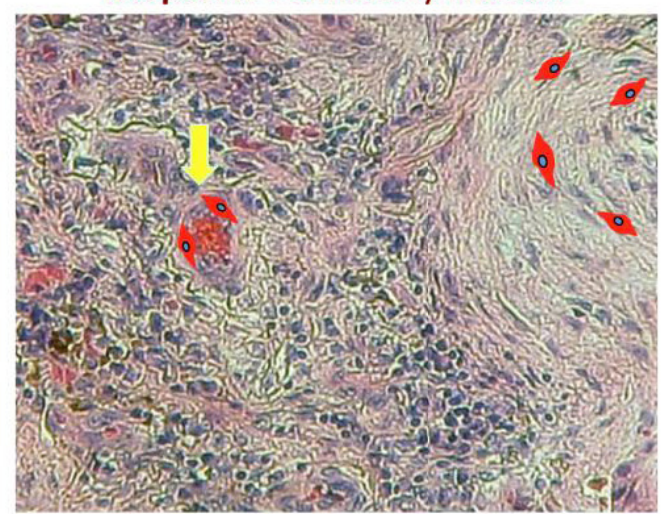

Progression to Fibroproliferative Disease PAH, PF, Emphysema, CLD, Asthma, BOS

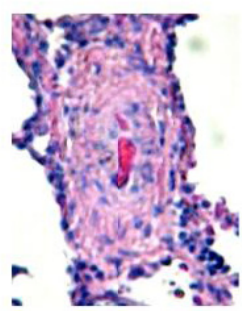

PAH Arteriole 


\subsection{Stem Cell Therapy \& Pulmonary Disease}

Inflammatory lung diseases are a major cause of morbidity and mortality. There is an increasing emphasis on the development of cell-based therapies to address these conditions, but the lung is a recalcitrant candidate for these strategies because of the diverse cell types and functions. A common thread linking these diseases is the proliferation of myofibroblast cells that contribute to remodeling as opposed to repair. Because myofibroblast proliferation is a characteristic of wound healing one may suppose that proliferative lung diseases are deregulated tissue repair. Additionally, there is a pervasive lack of understanding of how chronic disease processes affect tissue resident stem cell differentiation. The functional and differentiation programs of such stem cells, is likely altered by their transformation into myofibroblasts that participate in remodeling, rather than repair. Therefore, prior to testing cell-based therapy it is desirable to use pre-clinical animal models of lung disease to determine how changes in the lung tissue during the development of disease affect resident stem cell differentiation and function, including lung MSCs.

\subsection{Multipotent Resident Lung MSCs}

The functionality or 'stemness' of stem cells is highly influenced by the local microenvironment or niche. Thus, disease processes that alter this niche impair the capacity of its resident stem cells to function, undergo self-renewal, proliferate and properly differentiate [2,3]. Adult pulmonary tissue resident MSCs demonstrate a phenotype and function similar to BM-MSCs and have been identified in the side population (SP) of cells from both murine and human lung tissue [4,5] as well as bronchoalveolar lavage fluid from human lung allografts [6]. Depending on their microenvironment, the lung MSCs demonstrate properties similar to other tissue MSCs including multilineage differentiation, paracrine anti-inflammatory properties, suppression of $\mathrm{T}$ cell proliferation as well as the ability to differentiate to myofibroblasts [4-7].

Tissue resident mesenchymal stem cells (MSCs) are important regulators of tissue repair or regeneration, fibrosis, inflammation, angiogenesis and tumor formation. Lung MSCs have been identified and characterized by using flow cytometry to detect Hoechst 33342 vital dye efflux by lung cells in combination with absence of the hematopoietic marker, CD45. In vitro, these Hoechst33342 ${ }^{\mathrm{dim}} \mathrm{CD} 45^{\text {neg }}$ cells demonstrate multilineage mesenchymal differentiation potential to osteocyte, adipocyte and chondrocytes lineages and express the characteristic mesenchymal cell surface determinants ABCG2, CD90, CD105, CD106, CD73, CD44 and ScaI. In addition, they lack the hematopoietic markers c-kit and CD34 [4,5,7-9]. Lung MSCs also exhibit high telomerase activity which indicates the capacity for self-renewal $[4,5,7]$. The expression of high levels of telomerase, gives MSCs the ability to survive and replicate to generate many more offspring than typical somatic cells, similar to cancer cells [4,5,7-9]. These properties allow a small number of cells to contribute substantially to both tissue regeneration and to proliferative diseases [3,7-14].

Lama et al. and Hennrick et al. identified an additional population of MSCs derived from bronchoalveolar lavage fluid in patient allograft tissue or tracheal aspirates from ventilated neonates, respectively $[6,15]$. The human lung MSCs demonstrated a mesenchymal signature, multilineage differentiation to bone, fat and cartilage, myofibroblasts as well as combined expression of STRO-1, 
CD73, CD90, CD105, CD166, CCR2b, CD13, prolyl 4-hydroxylase and lack of CD11b, CD31, CD14, CD34 and CD45. Furthermore, MSCs isolated from tissue allograft bronchoalveolar lavage fluid also suppressed T cell proliferation $[7,16,17]$.

Pulmonary arterial hypertension (PAH) results from vasoconstriction, remodeling of the large and small pulmonary arteries and occlusion of microvessels in the lung (Figure 1). The PAH mortality rate in adult is 50 percent within five years after diagnosis. PAH may be heritable and termed familial or HPAH, idiopathic and a secondary complication of many adult lung diseases such as chronic obstructive pulmonary disease (COPD/emphysema) and pulmonary fibrosis (PF). Functional studies of the Hoechst $33342^{\mathrm{dim}} \mathrm{CD} 45^{\text {neg }}$ resident lung MSCs demonstrate that they regulate the severity of bleomycin injury via modulation of the T-cell response [7]. Jun et al. elegantly documented that bleomycin treatment of mice induced the loss of these endogenous lung MSCs and elicited fibrosis (PF), inflammation and pulmonary arterial hypertension. Replacement of resident stem cells by administration of isolated lung MSCs attenuated the bleomycin-associated pathology and mitigated the development of pulmonary arterial hypertension. In addition, lung MSCs modulated a decrease in numbers of inflammatory cells in bronchoalveolar lavage fluid and inhibition T cell proliferation. Gene expression analysis indicated that lung MSCs are a bona fide subpopulation of pulmonary mesenchyme, differing from lung fibroblasts in terms of pro-inflammatory mediators and pro-fibrotic pathways. These data suggest that lung MSCs function to protect lung integrity following injury however when endogenous MSCs are lost this function is compromised. Therefore, similar to other tissue resident stem cells, lung MSCs may regulate their native tissue repair. The rigorous characterization of cell surface markers facilitated the detection as well as co-localization of both murine and human lung tissue MSCs with the alveolar capillary network suggesting that these cells play a role in maintenance of the distal lung [7].

In addition to their reparative properties, several studies indicate that lung MSCs, under certain conditions; mediate pathogenic changes within the lung [18,19]. Indeed, the behavior of MSCs is highly sensitive to the microenvironment to which these cells are exposed [20]. As an example, it was recently shown that TGF- $\beta$ expression within the lungs of premature infants stimulates MSCs to differentiate into myofibroblasts [21] (Figure 1). This is significant as myofibroblasts induce dysfunctional matrix remodeling that results in the development of the chronic lung disease, bronchopulmonary dysplasia which is characterized by thickened septae and decreased functionality of the alveolar-capillary surfaced for gas exchange [22]. Similar findings were observed in lung allografts from transplanted patients [23]. In this study, lung derived MSCs isolated from the airways had increased expression of type I collagen and $\alpha$-smooth muscle actin and readily differentiated into myofibroblasts upon treatment with IL-13 or TGF- $\beta$ [23]. Allograft survival is limited by bronchiolitis obliterans, a fibrotic constriction of the airways [24]. Those MSCs from BOS subjects had a profibrotic phenotype indicating that this cell type was an important mediator of the fibrotic changes. Thus, these findings indicate that MSCs are a critical factor in the development of dysfunctional lung remodeling in these diseases.

Aside from affecting fibrotic disorders, MSCs can affect diseases like asthma that are characterized by lung inflammation and remodeling. Asthma is an inflammatory disorder that is typified by a proliferation of airway smooth muscle cells and the accumulation of myofibroblasts in airway subepithelium [25]. These changes promote airway obstruction and render the patient less responsive 
to bronchodilators [26]. Lung MSCs differentiate into these cell types and the numbers of myofibroblasts are significantly increased within the lungs of asthmatic patients [27]. Moreover, lung MSCs are increased in the ova sensitization asthma model suggesting that an aerosol challenge may act through lung MSCs to promote processes that lead to the development of asthma [28]. Together, these studies demonstrate that the biological effects of MSCs are highly influenced by the microenvironment in which they reside. Understanding these effects will better enable researchers to harness the reparative and immunomodulatory properties of MSCs while preventing the pathological remodeling changes that they induce in the lung.

\section{PDGF-BB ad Wnt: Two Key Signaling Targets in Inflammatory Lung Disease and Vascular Remodeling}

Maladaptive proliferation of vascular and myofibroblast cells is a hallmark of many lung diseases. These cells, as presumably lung MSCs, respond to the pulmonary microenvironment, which is likely impairing repair and regeneration. PDGF and Wnt signaling are two key pathways involved in the "programming” of MSC.

\subsection{PDGF-BB Signaling \& Fibro-Proliferative Lung Disorders}

PDGF-BB is expressed at low levels in adult lung parenchyma, endothelium, platelets and macrophages. Lung mesenchymal cells express high levels of PDGFR $\beta$ and respond to increases in PDGF-BB with proliferation and collagen production [29,30]. Its expression is up-regulated in lung parenchyma following animal exposure to low oxygen tension, hypobaric hypoxia and mechanical stress [30-35]. Similarly, PDGF-BB promotes loss of quiescence and differentiation to a proliferative myofibroblast phenotype of hepatic stellate cells [36]. Elevated levels of PDGF are evident in lung fibrosis (Figure 1), bronchiolotis obliterans pneumonia, post-transplant obliterative bronchiolitis, histiocytosis X, pneumoconiosis and fibrosis associated with PAH [29]. In PAH a layer of myofibroblasts and matrix accumulates between the EC and internal elastic lamina. The mechanisms involved in this process remain largely unknown [30]. PDGF levels also increase in lavage fluid following acute lung injury and prior to onset of symptoms in Hermansky-Pudlak syndrome [29]. Studies using in vivo and in vitro models of vascular neointimal thickening following various injuries have substantiated a role for PDGF-BB during this pathological process [37-41]. Inhibition of PDGFB signaling with multiple inhibitors attenuates pulmonary fibrosis and PAH by blocking fibroblast proliferation, muscularization of the vasculature, intimal thickening and matrix deposition $[33,34,42,43]$. However, the interpretation of these studies is limited by the varying specificity of the inhibitors. These studies elegantly link PDGF-BB signaling to the transition of the mesenchyme to a profibrotic phenotype that disrupts the normal pulmonary architecture.

MSC derived from bone marrow constitutively express PDGF-B and the addition of exogenous protein promotes their growth and differentiation [44]. PDGF-BB receptor, PDGFR $\beta$, is pivotal in the adhesion and migration of MSC through regulation of integrin binding to fibronectin suggesting that fibronectin rich matrix may recruit these cells to sites of remodeling or wound healing [45]. PDGF-B exposure also stimulates MSC differentiation to pericytes which then migrate to stabilize newly formed vasculature in tumors [46]. Taken together these studies provide a basis to investigate PDGF 
dependent mechanisms that define endogenous lung MSCs and the differentiation of other multipotent stem cells during disease in order to identify interventions and facilitate repair.

\subsection{Wnt Signaling in Fibro-Proliferative Lung Disorders}

The Wnt family of proteins is a highly conserved group of signaling molecules important in fundamental biological process including development and repair. $\beta$-catenin protein is a central mediator of canonical Wnt signaling via coactivation of TCF/LEF transcription factors [47-53]. $\beta$-catenin is regulated at the level of synthesis, activation/translocation to the nucleus and proteasomal degradation through a destruction complex (CKI and GSK kinases) [47-53]. Constitutive activation of the pathway due to mutations in $\beta$-catenin result in changes in cell fate specification during development and in adulthood as well as tumor formation [52]. Sustained activation of $\beta$-catenin can result in hypercellularity of tissue and deregulated self-renewal [49,53]. In BM-derived MSCs autocrine Wnt signaling regulates self-renewal and lineage specific differentiation, including osteocyte, chondrocytes and adipocyte [47,48,50,51,54].

Wnt signals through the canonical pathway involving $\beta$-catenin and through non-canonical pathways involving protein kinase $\mathrm{C}$ (PKC) [55] and MAPK8 (also known as JNK1) [56]. In the canonical pathway, binding of Wnt to its receptor triggers the translocation of $\beta$-catenin to the nucleus where it turns on gene expression by displacing the transcription inhibitor Groucho/HDAC from the T-cell specific factor (TCF)/lymphoid enhancer binding factor-1 (LEF1). The genes induced by $\beta$-catenin regulate MSC proliferation, differentiation [57], migration [58] and survival [59]. The non-canonical pathways do not act through $\beta$-catenin and in some cases they actually antagonize $\beta$-catenin signaling. Non-canonical Wnt pathways regulate the proliferation and differentiation of MSCs via Dvl or $\mathrm{Ca}^{++}$-dependent processes [51]. However, the effects of Wnt signaing on MSCs are quite complex. Not only can the canonical and non-canonical pathways antagonize each other but also Wnt concentration can affect signaling responses. Indeed, one study showed that low dose Wnt treatment stimulated MSC proliferation while high dose treatment inhibited it [60]. Adding further complexity to the effects of Wnts of MSCs is the presence of an elaborate network of negative regulators that block receptor binding or intracellular signaling to tightly control Wnt signaling. Wnt inhibitory factor (WIF-1) and secreted frizzled related proteins (SFRPs) bind soluble Wnts and inhibit interaction with the frizzled receptor [61] thereby antagonizing their action. In contrast, Dickkopfs (Dkks) and Sclerostins target the LRP receptors and prevent the propagation of intracellular signals through these receptors [62,63]. During osteocyte development, SFRPs regulate MSC differentiation [64] and apoptosis [65] and WIF-1 completely counteracted the Wnt3a mediated inhibition of MSC differentiation into chondrocytes [66]. Studies indicate that Dkks promote MSC proliferation while at the same time maintaining those cells in an undifferentiated state [67]. Though study in this field is just emerging, evidence indicates that the Wnt signaling pathway and its inhibitors will be key determinants of the effects of MSCs within the lung. Already studies have shown that the Wnt/ $\beta$-catenin pathway attenuates experimental emphysema [68] and the Wnt inhibitor SFRP-1 up regulates the expression of proteases that are important in the development of human emphysema [69]. Conversely, during lung fibrosis, activation of the Wnt pathway is present in proliferative myofibroblast lesions and plays an important role in the fibrotic changes that occur [70]. Further 
studies are needed to understand how Wnt signaling and MSCs interact to modulate the development of pathogenic changes in the lung. This promises to be a complex process to decipher as the effects of Wnts depend on the specific cell type, disease process and expression of counter regulatory inhibitory molecules.

\section{Conclusions}

In conclusion, studies are needed to fill gaps in our understanding of how resident lung MSCs are impaired during disease and their role during the development of disease which will be useful for designing further intervention.

\section{Acknowledgments}

The authors would like to thank Jim Loyd and Lisa Wheeler and the Vanderbilt Tissue Resource for providing histological samples depicted. This work was supported by R.F.: Flight Attendant Medical Research Institute (YCSA 24039); CIA 074047, US National Institutes of Health 5R01HL098528-04 and S.M.M.: AHA GIA0855953G, US National Institutes of Health/NHLBI 1R01 HL091105-01.

\section{Conflict of Interest}

The authors have no conflicts to disclose.

\section{References}

1. Beers, M.F.; Morrissey, E.E. The three R's of lung health and disease: Repair, remodeling, and regeneration. J. Clin. Invest. 2011, 121, 2065-2073.

2. Scadden, D.T. The stem-cell niche as an entity of action. Nature 2006, 441, 1075-1079.

3. Volckaert, T.; Dill, E.; Campbell, A.; Tiozzo, C.; Majka, S.; Bellusci, S.; de Langhe, S.P. Parabronchial smooth muscle constitutes an airway epithelial stem cell niche in the mouse lung after injury. J. Clin. Invest. 2011, 121, 4409-4419.

4. Martin, J.; Helm, K.; Ruegg, P.; Varella-Garcia, M.; Burnham, E.; Majka, S. Adult lung side population cells have mesenchymal stem cell potential. Cytotherapy 2008, 10, 140-151.

5. Summer, R.; Fitzsimmons, K.; Dwyer, D.; Murphy, J.; Fine, A. Isolation of an adult mouse lung mesenchymal progenitor cell population. Am. J. Respir. Cell Mol. Biol. 2007, 37, 152-159.

6. Lama, V.N.; Smith, L.; Badri, L.; Flint, A.; Andrei, A.-C.; Murray, S.; Wang, Z.; Liao, H.; Toews, G.B.; Krebsbach, P.H.; et al. Evidence for tissue-resident mesenchymal stem cells in human adult lung from studies of transplanted allografts. J. Clin. Invest. 2007, 117, 989-996.

7. Jun, D.; Garat, C.; West, J.; Thorn, N.; Chow, K.; Cleaver, T.; Sullivan, T.; Torchia, E.C.; Childs, C.; Shade, T.; et al. The pathology of bleomycin-induced fibrosis is associated with loss of resident lung mesenchymal stem cells that regulate effector T-cell proliferation. Stem Cell. 2011, $29,725-735$.

8. Chateauvieux, S.; Ichanté, J.-L.; Delorme, B.; Frouin, V.; Piétu, G.; Langonné, A.; Gallay, N.; Sensebé, L.; Martin, M.T.; Moore, K.A.; et al. Molecular profile of mouse stromal mesenchymal stem cells. Physiol. Genom. 2007, 29, 128-138. 
9. McQualter, J.L.; Brouard, N.; Williams, B.; Baird, B.N.; Sims-Lucas, S.; Yuen, K.; Nilsson, S.K.; Simmons, P.J.; Bertoncello, I. Endogenous fibroblastic progenitor cells in the adult mouse lung are highly enriched in the Sca-1 positive cell fraction. Stem Cell. 2009, 27, 623-633.

10. Aslam, M.; Baveja, R.; Liang, O.D.; Fernandez-Gonzalez, A.; Lee, C.; Mitsialis, S.A.; Kourembanas, S. Bone marrow stromal cells attenuate lung injury in a murine model of neonatal chronic lung disease. Am. J. Respir. Crit. Care Med. 2009, 180, 1122-1130.

11. Lee, R.H.; Pulin, A.A.; Seo, M.J.; Kota, D.J.; Ylostalo, J.; Larson, B.L.; Semprun-Prieto, L.; Delafontaine, P.; Prockop, D.J. Intravenous hMSCs Improve myocardial infarction in mice because cells embolized in lung are activated to secrete the anti-inflammatory protein TSG-6. Cell Stem Cell 2009, 5, 54-63.

12. Tsai, M.-S.; Hwang, S.-M.; Chen, K.-D.; Lee, Y.-S.; Hsu, L.-W.; Chang, Y.-J.; Wang, C.-N.; Peng, H.-H.; Chang, Y.-L.; Chao, A.-S.; et al. Functional network analysis of the transcriptomes of mesenchymal stem cells derived from amniotic fluid, amniotic membrane, cord blood, and bone marrow. Stem Cell. 2007, 25, 2511-2523.

13. Benvenuto, F.; Ferrari, S.; Gerdoni, E.; Gualandi, F.; Frassoni, F.; Pistoia, V.; Mancardi, G.; Uccelli, A. Human mesenchymal stem cells promote survival of $\mathrm{T}$ cells in a quiescent state. Stem Cell. 2007, 25, 1753-1760.

14. Fatima, S.; Zhou, S.; Sorrentino, B.P. Abcg2 expression marks tissue-specific stem cells in multiple organs in a mouse progeny tracking model. Stem Cell. 2011, 30, 210-221.

15. Hennrick, K.T.; Keeton, A.G.; Nanua, S.; Kijek, T.G.; Goldsmith, A.M.; Sajjan, U.S.; Bentley, J.K.; Lama, V.N.; Moore, B.B.; Schumacher, R.E.; et al. Lung cells from neonates show a mesenchymal stem cell phenotype. Am. J. Respir. Crit. Care Med. 2007, 175, 1158-1164.

16. Jarvinen, L.; Badri, L.; Wettlaufer, S.; Ohtsuka, T.; Standiford, T.J.; Toews, G.B.; Pinsky, D.J.; Peters-Golden, M.; Lama, V.N. Lung resident mesenchymal stem cells isolated from human lung allografts inhibit T cell proliferation via a soluble mediator. J. Immunol. 2008, 181, 4389-4396.

17. Lee, J.W.; Gupta, N.; Serikov, V.; Matthay, M.A. Potential application of mesenchymal stem cells in acute lung injury. Expet. Opin. Biol. Ther. 2009, 9, 1259-1270.

18. Bonner, J.C. Mesenchymal cell survival in airway and interstitial pulmonary fibrosis. Fibrogenesis Tissue Repair 2010, 3, 15.

19. Pierro, M.; Thebaud, B. Mesenchymal stem cells in chronic lung disease: Culprit or savior? Am. J. Physiol. Lung Cell. Mol. Physiol. 2010, 298, L732-734.

20. Yan, X.; Liu, Y.; Han, Q.; Jia, M.; Liao, L.; Qi, M.; Zhao, R.C. Injured microenvironment directly guides the differentiation of engrafted Flk-1(+) mesenchymal stem cell in lung. Exp. Hematol. 2007, 35, 1466-1475.

21. Popova, A.P.; Bozyk, P.D.; Bentley, J.K.; Linn, M.J.; Goldsmith, A.M.; Schumacher, R.E.; Weiner, G.M.; Filbrun, A.G.; Hershenson, M.B. Isolation of tracheal aspirate mesenchymal stromal cells predicts bronchopulmonary dysplasia. Pediatrics 2010, 126, e1127-1133.

22. Toti, P.; Buonocore, G.; Tanganelli, P.; Catella, A.M.; Palmeri, M.L.; Vatti, R.; Seemayer, T.A. Bronchopulmonary dysplasia of the premature baby: An immunohistochemical study. Pediatr. Pulmonol. 1997, 24, 22-28. 
23. Walker, N.; Badri, L.; Wettlaufer, S.; Flint, A.; Sajjan, U.; Krebsbach, P.H.; Keshamouni, V.G.; Peters-Golden, M.; Lama, V.N. Resident tissue-specific mesenchymal progenitor cells contribute to fibrogenesis in human lung allografts. Am. J. Pathol. 2011, 178, 2461-2469.

24. Todd, J.L.; Palmer, S.M. Bronchiolitis obliterans syndrome: The final frontier for lung transplantation. Chest 2011, 140, 502-508.

25. Descalzi, D.; Folli, C.; Scordamaglia, F.; Riccio, A.M.; Gamalero, C.; Canonica, G.W. Importance of fibroblasts-myofibroblasts in asthma-induced airway remodeling. Recent Pat. Inflamm. Allergy Drug Discov. 2007, 1, 237-241.

26. Al-Muhsen, S.; Johnson, J.R.; Hamid, Q. Remodeling in asthma. J. Allergy Clin. Immunol. 2011, 128, 451-462; quiz 463- quiz 454.

27. Brewster, C.E.; Howarth, P.H.; Djukanovic, R.; Wilson, J.; Holgate, S.T.; Roche, W.R. Myofibroblasts and subepithelial fibrosis in bronchial asthma. Am. J. Respir. Cell Mol. Biol. 1990, 3, 507-511.

28. Bentley, J.K.; Popova, A.P.; Bozyk, P.D.; Linn, M.J.; Baek, A.E.; Lei, J.; Goldsmith, A.M.; Hershenson, M.B. Ovalbumin sensitization and challenge increases the number of lung cells possessing a mesenchymal stromal cell phenotype. Respir. Res. 2010, 11, 127.

29. Heldin, C.-H.; Westermark, B. Mechanism of action and in vivo role of platelet-derived growth factor. Physiol. Rev. 1999, 79, 1283-1316.

30. Barst, R.J. PDGF signaling in pulmonary arterial hypertension. J. Clin. Invest. 2005, 115, 2691-2694.

31. Berg, J.Ä.; Breen, E.̈̈.; Fu, Z.; Mathieu-Costello, O.; West, J.Ä. Alveolar hypoxia increases gene expression of extracellular matrix proteins and platelet-derived growth factor-B in lung parenchyma. Am. J. Respir. Crit. Care Med. 1998, 158, 1920-1928.

32. Humbert, M.; Morrell, N.W.; Archer, S.L.; Stenmark, K.R.; MacLean, M.R.; Lang, I.M.; Christman, B.W.; Weir, E.K.; Eickelberg, O.; Voelkel, N.F.; et al. Cellular and molecular pathobiology of pulmonary arterial hypertension. J. Am. Coll. Cardiol. 2004, 43, S13-S24.

33. Schermuly, R.T.; Dony, E.; Ghofrani, H.A.; Pullamsetti, S.; Savai, R.; Roth, M.; Sydykov, A.; Lai, Y.J.; Weissmann, N.; Seeger, W.; et al. Reversal of experimental pulmonary hypertension by PDGF inhibition. J. Clin. Invest. 2005, 115, 2811-2821.

34. Ghofrani, H.A.; Seeger, W.; Grimminger, F. Imatinib for the treatment of pulmonary arterial hypertension. New Engl. J. Med. 2005, 353, 1412-1413.

35. Lamé, M.W.; Jones, A.D.; Wilson, D.W.; Segall, H.J. Monocrotaline pyrrole targets proteins with and without cysteine residues in the cytosol and membranes of human pulmonary artery endothelial cells. Proteomics 2005, 5, 4398-4413.

36. Adachi, M.; Osawa, Y.; Uchinami, H.; Kitamura, T.; Accili, D.; Brenner, D.A. The forkhead transcription factor FoxO1 regulates proliferation and transdifferentiation of hepatic stellate cells. Gastroenterology 2007, 132, 1434-1446.

37. Desfaits, A.-C.C.; Raymond, J. Growth factors stimulate neointimal cells in vitro and increase the thickness of the neointima formed at the neck of porcine aneurysms treated by embolization. Stroke 2000, 31, 498-507. 
38. Fishbein, I.; Waltenberger, J.; Banai, S.; Rabinovich, L.; Chorny, M.; Levitzki, A.; Gazit, A.; Huber, R.; Mayr, U.; Gertz, S.D.; et al. Local delivery of platelet-derived growth factor receptorspecific tyrphostin inhibits neointimal formation in rats. Arterioscler. Thromb. Vasc. Biol. 2000, 20, 667-676.

39. Sirois, M.G.; Simons, M.; Edelman, E.R. Antisense oligonucleotide inhibition of PDGFR-beta receptor subunit expression directs suppression of intimal thickening. Circulation 1997, 95, 669-676.

40. Sheu, J.-R.; Wu, C.-H.; Chen, Y.-C.; Hsiao, G.; Lin, C.-H. Mechanisms in the inhibition of neointimal hyperplasia with triflavin in a rat model of balloon angioplasty. J. Lab. Clin. Med. 2001, 137, 270-278.

41. Battegay, E.J.; Rupp, J.; Iruela-Arispe, L.; Sage, E.H.; Pech, M. PDGF-BB modulates endothelial proliferation and angiogenesis in vitro via PDGF beta-receptors. J. Cell Biol. 1994, 125, 917-928.

42. Abdollahi, A.; Li, M.; Ping, G.; Plathow, C.; Domhan, S.; Kiessling, F.; Lee, L.B.; McMahon, G.; Gröne, H.-J.; Lipson, K.E.; et al. Inhibition of platelet-derived growth factor signaling attenuates pulmonary fibrosis. J. Exp. Med. 2005, 201, 925-935.

43. Wang, S.; Wilkes, M.C.; Leof, E.B.; Hirschberg, R. Imatinib mesylate blocks a non-Smad TGF- $\beta$ pathway and reduces renal fibrogenesis in vivo. FASEB J. 2005, 19, 1-11.

44. Ng, F.; Boucher, S.; Koh, S.; Sastry, K.S.R.; Chase, L.; Lakshmipathy, U.; Choong, C.; Yang, Z.; Vemuri, M.C.; Rao, M.S.; et al. PDGF, TGF-beta, and FGF signaling is important for differentiation and growth of mesenchymal stem cells (MSCs): Transcriptional profiling can identify markers and signaling pathways important in differentiation of MSCs into adipogenic, chondrogenic, and osteogenic lineages. Blood 2008, 112, 295-307.

45. Veevers-Lowe, J.; Ball, S.G.; Shuttleworth, A.; Kielty, C.M. Mesenchymal stem cell migration is regulated by fibronectin through $\alpha 5 \beta 1$-integrin-mediated activation of PDGFR- $\beta$ and potentiation of growth factor signals. J. Cell Sci. 2011, 124, 1288-1300.

46. Dhar, K.; Dhar, G.; Majumder, M.; Haque, I.; Mehta, S.; van Veldhuizen, P.J.; Banerjee, S.K.; Banerjee, S. Tumor cell-derived PDGF-B potentiates mouse mesenchymal stem cells-pericytes transition and recruitment through an interaction with NRP-1. Mol. Cancer 2010, 9, 209.

47. Baksh, D.; Boland, G.M.; Tuan, R.S. Cross-talk between Wnt signaling pathways in human mesenchymal stem cells leads to functional antagonism during osteogenic differentiation. J. Cell. Biochem. 2007, 101, 1109-1124.

48. Etheridge, S.L.; Spencer, G.J.; Heath, D.J.; Genever, P.G. Expression profiling and functional analysis of Wnt signaling mechanisms in mesenchymal stem cells. Stem Cell. 2004, 22, 849-860.

49. Kalani, M.Y.S.; Cheshier, S.H.; Cord, B.J.; Bababeygy, S.R.; Vogel, H.; Weissman, I.L.; Palmer, T.D.; Nusse, R. Wnt-mediated self-renewal of neural stem/progenitor cells. Proc. Natl. Acad. Sci. U.S. A. 2008, 105, 16970-16975.

50. Kirton, J.P.; Crofts, N.J.; George, S.J.; Brennan, K.; Canfield, A.E. Wnt/ $\beta$-catenin signaling stimulates chondrogenic and inhibits adipogenic differentiation of pericytes. Circ. Res. 2007, 101, 581-589.

51. Ling, L.; Nurcombe, V.; Cool, S.M. Wnt signaling controls the fate of mesenchymal stem cells. Gene 2009, 433, 1-7.

52. Reya, T.; Clevers, H. Wnt signalling in stem cells and cancer. Nature 2005, 434, 843-850. 
53. Reya, T.; Duncan, A.W.; Ailles, L.; Domen, J.; Scherer, D.C.; Willert, K.; Hintz, L.; Nusse, R.; Weissman, I.L. A role for Wnt signalling in self-renewal of haematopoietic stem cells. Nature 2003, 423, 409-414.

54. Berg, T.; DeLanghe, S.; Al Alam, D.; Utley, S.; Estrada, J.; Wang, K.S. $\beta$-catenin regulates mesenchymal progenitor cell differentiation during hepatogenesis. J. Surg. Res. 2010, 164, 276-285.

55. Kuhl, M.; Sheldahl, L.C.; Malbon, C.C.; Moon, R.T. Ca(2+)/calmodulin-dependent protein kinase II is stimulated by Wnt and Frizzled homologs and promotes ventral cell fates in Xenopus. J. Biol. Chem. 2000, 275, 12701-12711.

56. Boutros, M.; Paricio, N.; Strutt, D.I.; Mlodzik, M. Dishevelled activates JNK and discriminates between JNK pathways in planar polarity and wingless signaling. Cell 1998, 94, 109-118.

57. Cohen, E.D.; Ihida-Stansbury, K.; Lu, M.M.; Panettieri, R.A.; Jones, P.L.; Morrisey, E.E. Wnt signaling regulates smooth muscle precursor development in the mouse lung via a tenascin C/PDGFR pathway. J. Clin. Invest. 2009, 119, 2538-2549.

58. Badri, L.; Lama, V.N. Lysophosphatidic acid induces migration of human lung-resident mesenchymal stem cells through the beta-catenin pathway. Stem Cell. 2012, 30, 2010-2019.

59. Deng, L.; Hu, S.; Baydoun, A.R.; Chen, J.; Chen, X.; Cong, X. Aspirin induces apoptosis in mesenchymal stem cells requiring Wnt/beta-catenin pathway. Cell Prolif. 2009, 42, 721-730.

60. De Boer, J.; Wang, H.J.; van Blitterswijk, C. Effects of Wnt signaling on proliferation and differentiation of human mesenchymal stem cells. Tissue Eng. 2004, 10, 393-401.

61. Uren, A.; Reichsman, F.; Anest, V.; Taylor, W.G.; Muraiso, K.; Bottaro, D.P.; Cumberledge, S.; Rubin, J.S. Secreted frizzled-related protein-1 binds directly to Wingless and is a biphasic modulator of Wnt signaling. J. Biol. Chem. 2000, 275, 4374-4382.

62. Leyns, L.; Bouwmeester, T.; Kim, S.H.; Piccolo, S.; de Robertis, E.M. Frzb-1 is a secreted antagonist of Wnt signaling expressed in the Spemann organizer. Cell 1997, 88, 747-756.

63. Semenov, M.V.; Tamai, K.; Brott, B.K.; Kuhl, M.; Sokol, S.; He, X. Head inducer Dickkopf-1 is a ligand for Wnt coreceptor LRP6. Curr. Biol. 2001, 11, 951-961.

64. Cho, S.W.; Her, S.J.; Sun, H.J.; Choi, O.K.; Yang, J.Y.; Kim, S.W.; Kim, S.Y.; Shin, C.S. Differential effects of secreted frizzled-related proteins (sFRPs) on osteoblastic differentiation of mouse mesenchymal cells and apoptosis of osteoblasts. Biochem. Biophys. Res. Commun. 2008, 367, 399-405.

65. Bodine, P.V.; Billiard, J.; Moran, R.A.; Ponce-de-Leon, H.; McLarney, S.; Mangine, A.; Scrimo, M.J.; Bhat, R.A.; Stauffer, B.; Green, J.; et al. The Wnt antagonist secreted frizzled-related protein-1 controls osteoblast and osteocyte apoptosis. J. Cell. Biochem. 2005, 96, 1212-1230.

66. Surmann-Schmitt, C.; Widmann, N.; Dietz, U.; Saeger, B.; Eitzinger, N.; Nakamura, Y.; Rattel, M.; Latham, R.; Hartmann, C.; von der Mark, H.; et al. Wif-1 is expressed at cartilagemesenchyme interfaces and impedes Wnt3a-mediated inhibition of chondrogenesis. J. Cell Sci. 2009, 122, 3627-3637.

67. Horwitz, E.M. Dkk-1-mediated expansion of adult stem cells. Trends Biotechnol. 2004, 22, $386-388$. 
68. Kneidinger, N.; Yildirim, A.O.; Callegari, L.; Takenaka, S.; Stein, M.M.; Dumitrascu, R.; Bohla, A.; Bracke, K.R.; Morty, R.E.; Brusselle, G.G.; et al. Activation of the WNT/beta-catenin pathway attenuates experimental emphysema. Am. J. Respir. Crit. Care Med. 2011, 183, 723-733.

69. Foronjy, R.; Imai, K.; Shiomi, T.; Mercer, B.; Sklepkiewicz, P.; Thankachen, J.; Bodine, P.; D'Armiento, J. The divergent roles of secreted frizzled related protein-1 (SFRP1) in lung morphogenesis and emphysema. Am. J. Pathol. 2010, 177, 598-607.

70. Konigshoff, M.; Kramer, M.; Balsara, N.; Wilhelm, J.; Amarie, O.V.; Jahn, A.; Rose, F.; Fink, L.; Seeger, W.; Schaefer, L.; et al. WNT1-inducible signaling protein-1 mediates pulmonary fibrosis in mice and is upregulated in humans with idiopathic pulmonary fibrosis. J. Clin. Invest. 2009, $119,772-787$.

(C) 2012 by the authors; licensee MDPI, Basel, Switzerland. This article is an open access article distributed under the terms and conditions of the Creative Commons Attribution license (http://creativecommons.org/licenses/by/3.0/). 